\title{
Prevalence of dysmenorrhoea and its effect on quality of life among nursing students
}

\author{
Vineeta Ghanghoriya, Kirti Patel*, Reenu Markam
}

Department of Obstetrics and Gynecology, NSCB. MCH Jabalpur, Madhya Pradesh, India

Received: 11 April 2018

Accepted: 16 April 2018

\section{*Correspondence:}

Dr. Kirti Patel,

E-mail: dr.kirtipate10107@gmail.com

Copyright: () the author(s), publisher and licensee Medip Academy. This is an open-access article distributed under the terms of the Creative Commons Attribution Non-Commercial License, which permits unrestricted non-commercial use, distribution, and reproduction in any medium, provided the original work is properly cited.

\begin{abstract}
Background: Painful menstruation, is common gynaecologic problem, significantly affects the routine life of most of affected girls. Most of them experience some degree of pain and discomfort during menstrual period, which can affect their daily activities, disturb their productivity at their work place. This also appears to be a leading cause of absenteeism from college. Hence arises a need to evaluate the, prevalence of dysmenorrhoea and its effect on daily routine activities and quality of life of nursing students.

Methods: This is a cross sectional study conducted among 100 nursing students $\left(1^{\text {st }}\right.$ year, $2^{\text {nd }}$ year and $3^{\text {rd }}$ year) of NSCB Medical College with the objectives to evaluate prevalence and severity of dysmenorrhea and its effects on the quality of life, particularly absenteeism from college/work place. Students chosen for study and each student was given questionnaire to complete background information, question related to menstrual cycle, severity of dysmenorrhoea, PMS, and work /study /daily activities affected due to dysmenorrhoea, elucidated and data collected and analysed.

Results: Prevalence of dysmenorrhoea was $79 \%$ of these $3 \%$ severe, $18 \%$ moderate and $58 \%$ were mild grade. Out of $79 / 100$ participants of dysmenorrhoea $63.29 \%$ missed individual classes or their study affected, $31.64 \%$ had to take leave from work place and $51.89 \%$ reported social withdrawal during menstruation due to dysmenorrhoea.7.59\% take medicines for pain relief.

Conclusions: Dysmenorrhoea is a very common problem among girls and it affects their quality of life and their productivity at work place. It is important to spread awareness about the causes and treatment of dysmenorrhoea to avoid undue sufferings causing absenteeism from work and studies.
\end{abstract}

Keywords: Absenteeism Dysmenorrhoea, Menstruation, Prevalence

\section{INTRODUCTION}

Dysmenorrhoea is defined as painful menstrual cramps of uterine origin. It is most common gynecologic complaint among adolescent and young adult females. ${ }^{1}$ It is often accompanied by other biological symptoms including dizziness, fatigue, sweating, backache, headache, nausea, vomiting, and diarrhea all occurring just before or during the menstruation. $10 \%$ of these suffer severely enough to render them incapacitated for one to three days each menstrual cycle. This situation not only has a significant effect on quality of life and personal health but also has a global economic impact. ${ }^{2}$ There is a wide variation in the estimate of dysmenorrhoea from studies around the world reporting a range between $28 \%$ and $71.7 \% .^{3,4}$ In similar studies from Turkey, the prevalence of dysmenorrhea has been reported to be between $58.2 \%$ and $89.5 \% .^{5,6}$

The true incidence and prevalence of dysmenorrhoea are not clearly established in India. Dysmenorrhoea has been estimated to be the greatest cause of time lost from work, colleges and schools. Despite the high prevalence of 
dysmenorrhoea, it is poorly treated and disregarded by health professionals, pain researchers, and the women themselves, who may accept it as a normal part of the menstrual cycle. Two categories of dysmenorrhoea are defined, primary and secondary. Primary dysmenorrhoea is defined as painful menses among females with normal pelvic anatomy, frequently beginning during adolescence. It is observed only in ovulatory cycles, frequently emerging within 6 to 12 months after menarche with no pathology or organic basis. Secondary dysmenorrhea is a menstrual pain associated with underlying pathology and its onset might be years after menarche and can occur premenstrually as well as during menstruation. Primary dysmenorrhoea is extremely common, especially among adolescents. $^{7}$ As many as $90 \%$ of adolescent females and above $50 \%$ of menstruating women worldwide report suffering from it, with $10-20 \%$ of them describing their hurt as severe and distressing. ${ }^{8}$

Overproduction of prostaglandins is a substantial contributing factor to the painful cramps. Premenstrual syndrome (PMS) is combination of physical and psychological symptoms that some women experience during the late luteal phase of each menstrual cycle ( 7 to 14 days prior to menstruation). ${ }^{9}$ Moderate to severe pain that affects lifestyle and does not respond to pharmacological treatment requires professional attention and appropriate diagnosis of possible underlying pelvic disease.
The present study aim to find the prevalence of dysmenorrhoea, its effect and consequences of recurrent menstrual pain, mood, quality of life, routine activity and productivity in nursing students with primary dysmenorrhea.

\section{METHODS}

This is cross-sectional descriptive study, carried out from Dec 2017 to Feb 2018 with objectives to rule out the Dysmenorrhoea related to menstruation in last three cycles. Study was conducted in Nursing students NSCB medical college Jabalpur MP.

A total of 100 female ( $1^{\text {st }}$ and $2^{\text {nd }}$ and $3^{\text {rd }}$ year) Nursing students were chosen for this study and each student was given a questionnaire (Proforma) to complete. Back ground information about the respondents include: age, education, weight, height, socioeconomic status, dietary habits, physical exercise.

Questions related to menstruation, elucidated variation in menstrual patterns like length of cycle, duration of bleeding period, blood loss per cycle, (number of pad used/cycle), Type of pad used, history of dysmenorrhoea and its severity, pre-menstrual symptom and absenteeism from college/classes/hospital, affected study/sports activity, medicines required for dysmenorrhoea. To detect the severity of dysmenorrhea we used the VerbalMultidimensional Scoring System. ${ }^{10}$

Table 1: Verbal Multi-dimensional scoring system (Severity of Dysmenorrhoea).

\begin{tabular}{|lllll|}
\hline Grade & $\begin{array}{l}\text { Severity of Dysmenorrhoea } \\
\text { Mc is not painful and daily activity is }\end{array}$ & Working ability & $\begin{array}{l}\text { Systemic } \\
\text { symptoms }\end{array}$ & $\begin{array}{l}\text { Need of } \\
\text { analgesic }\end{array}$ \\
\hline 1 & $\begin{array}{l}\text { Mc is painful but seldom inhibit normal } \\
\text { activity, mild pain. }\end{array}$ & Rarely affected & None & Rarely required \\
\hline 2 & $\begin{array}{l}\text { Daily activity affected, analgesic gives reliefso } \\
\text { that absence from work is unusal; moderate } \\
\text { pain }\end{array}$ & $\begin{array}{l}\text { Moderately } \\
\text { affected }\end{array}$ & Few & Required \\
\hline 3 & $\begin{array}{l}\text { Daily activity inhibited, poor effect of } \\
\text { analgesics, severe pain }\end{array}$ & Inhibited & $\begin{array}{l}\text { Headache, fatigue, } \\
\text { nausea, vomiting } \\
\text { and diarrhea. }\end{array}$ & Poor Effect \\
\hline
\end{tabular}

In the present study dysmenorrhoea was defined as having painful menstruation during the previous three months and the degree of pain was categorized as mild, moderate and severe.

Work place absence was defined as missing half day to complete day of work place and class absence was defined as missing individual classes because of pain during menstruation. ${ }^{11}$ Pre-menstrual syndrome (PMS) is recurrent variable cluster of trouble some physical and emotional symptoms that develop 7-14 days before the onset of menstruation and subsides when menstruation occurs.

This study included only unmarried nulliparous, healthy (1st, 2nd and 3rd year) nursing students, in age group of 17 to 25 years. The participation was purely on voluntarily basis and written consent was taken before initiating the data collection. 


\section{Statistical Analysis}

Data was double key entered in Microsoft Excel 2007 worksheet. All the inconsistencies and illogical entries were validated and restored before statistical analysis. Non-numerical variables were coded numerically. Categorical variables were tabulated in frequency and percent distribution. Odds Ratio with $95 \%$ confidence intervals were calculated.

Frequency distribution in contingency table was analysed using chi square analysis. Fisher"s exact test was also applied where frequency was less than 5. Statistical analysis was performed using SPSS 22 version for windows.

\section{RESULTS}

In the present study total 100 students participated and completed questionnaire. The mean age of participants was 19.28 year. The mean age at menarche was 13.41 year. Of the total participants $73 \%$ belongs to urban and $27 \%$ from rural area. $34 \%$ were pure vegetarian and $66 \%$ were on mixed diet. $66 \%$ has fast food habit. $69 \%$ subjects were average weight, while $21 \%$ subjects were underweight and $10 \%$ were overweight.

Out of 100 partcipants $45 \%$ involved in daily outdoor physical exercise for more than $30 \mathrm{~min}, 27 \%$ do no exercise while $28 \%$ involved in exercise for less than 30min duration (Table 2).

Table 2: Biological Characteristics of subjects.

\begin{tabular}{|c|c|c|c|c|}
\hline Variables & $(\mathrm{n}=100)$ & $\begin{array}{l}\text { Dysmenorrhoea } \\
\text { present }\end{array}$ & $\begin{array}{l}\text { Dysmenorrhoea } \\
\text { absent }\end{array}$ & OR(95\% CI) \\
\hline \multicolumn{5}{|l|}{ BMI (WHO criteria)* } \\
\hline Underweight $(\mathrm{BMI} \leq 18)$ & 21 & 16 & 5 & 1(Reference) \\
\hline Average weight (18-22.99) & 69 & 54 & 15 & $1.12(0.35-3.60)$ \\
\hline Overweight (23-30) & 8 & 7 & 1 & $2.19(0.20-23.71)$ \\
\hline Moderately obese >30) & 2 & 2 & 0 & - \\
\hline \multicolumn{5}{|l|}{ Exercise Duration** } \\
\hline No exercise & 27 & 26 & 1 & $15.78(1.63-153.14)$ \\
\hline$<30$ Min & 28 & 25 & 3 & $5.06(1.23-20.78)$ \\
\hline$\geq 30 \mathrm{Min}$ & 45 & 28 & 17 & 1(Reference) \\
\hline \multicolumn{5}{|l|}{ Diet (Fast food habit) $* * *$} \\
\hline Present & 66 & 56 & 10 & $2.68(0.98-7.35)$ \\
\hline Absent & 34 & 23 & 11 & 1(Reference) \\
\hline \multicolumn{5}{|l|}{ Age (in years) $)_{* * * *}$} \\
\hline 17 & 3 & 2 & 1 & 1(Reference) \\
\hline 18 & 20 & 16 & 4 & $2.00(0.13-30.18)$ \\
\hline 19 & 35 & 28 & 7 & $2.00(0.5-26.49)$ \\
\hline 20 & 33 & 24 & 9 & $1.33(0.10-17.20)$ \\
\hline 21 & 6 & 6 & 0 & - \\
\hline 22 & 3 & 3 & 0 & - \\
\hline \multicolumn{5}{|l|}{ Locality $* * * * *$} \\
\hline Urban & 73 & 56 & 17 & 1(Reference) \\
\hline 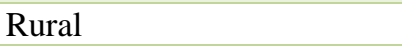 & 27 & 23 & 4 & $1.75(0.52-5.82)$ \\
\hline
\end{tabular}

Distribution of subjects with or without history of dismenorrhoea, according to age, BMI, locality, duration of exercise and fast food habit was shown in Table 2.

Prevalence of dysmenorrhoea was $79 \%$ (Figure 1) of these 3\%, Severe (95\% CI-0.62-8.52), $18 \%$ moderate (95\% CI-11.03-26.95) and 58\% were mild grade (95\%CI 47.71-67.80). Among these subject $(n=79)$ following symptoms ie; Backache $82.27 \%$, Lower abdomen pain (84.81\%), Fatigue (54.43\%), Vomiting (15.18\%), Headache $(32.91 \%)$ were reported (Figure 2).

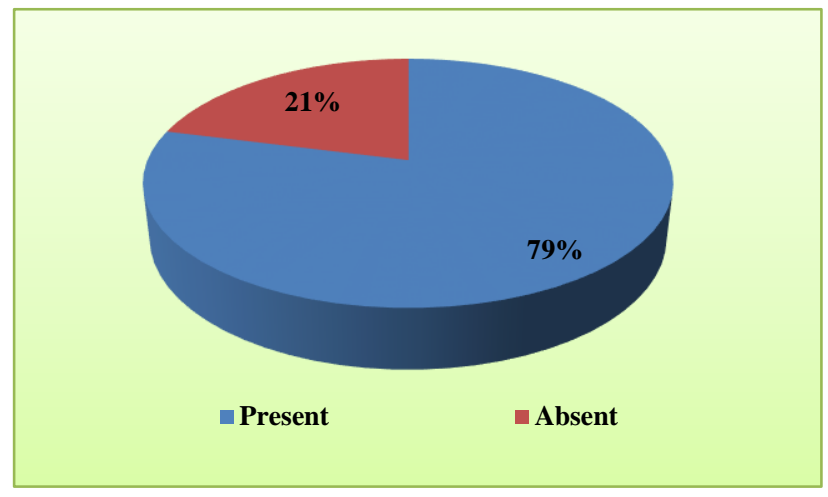

Figure 1: Prevalence of dysmenorrhoea. 
Out of 100 subjects, 64\% were presented with PMS, symptoms consist of systemic symptoms (64.06\%) like abdominal bloating, breast heaviness, neuropsychiatric symptoms $(53.12 \%)$ and behavioral symptoms $40.62 \%$ (Figure 3) (Figure 4).

Table 3: Characteristics of menstrual cycle.

\begin{tabular}{|c|c|c|}
\hline $\begin{array}{l}\text { Menstrual cycle } \\
\text { characteristics }\end{array}$ & $\begin{array}{l}\text { Number of Subjects } \\
(n=100)\end{array}$ & $\%$ \\
\hline \multicolumn{3}{|c|}{ Length of cycle (days) } \\
\hline$<20$ & 3 & 3 \\
\hline $20-35$ & 85 & 85 \\
\hline$>35$ & 12 & 12 \\
\hline \multicolumn{3}{|c|}{ Duration of Menses } \\
\hline$\leq 2$ & 3 & 3 \\
\hline $3-7$ & 93 & 93 \\
\hline$>7$ & 4 & 4 \\
\hline \multicolumn{3}{|c|}{ Blood loss /cycle (no of pad used/cycle) } \\
\hline$\leq 5$ & 6 & 6 \\
\hline $6-10$ & 48 & 48 \\
\hline $11-15$ & 33 & 33 \\
\hline $16-20$ & 8 & 8 \\
\hline$>20$ & 5 & 5 \\
\hline \multicolumn{3}{|c|}{ H/O Dysmenorrhoea } \\
\hline Yes & 79 & 79 \\
\hline No & 21 & 21 \\
\hline \multicolumn{3}{|c|}{ H/O Premenstrual Symptoms } \\
\hline Yes & 64 & 64 \\
\hline No & 36 & 36 \\
\hline
\end{tabular}

In $85 \%$ subject's length of cycle was normal (20-35days) while in $3 \%$ had short cycles (<20days) and $12 \%$ had longer cycles ( $>35$ days). Maximum subjects had average duration of bleeding (93\%) and Average amount of blood flow (Table 3).

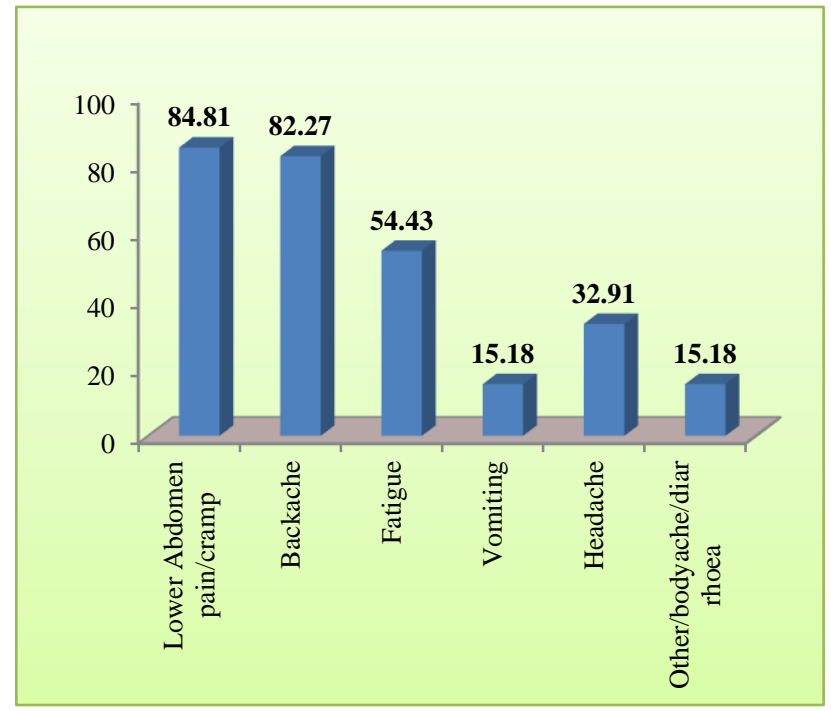

Figure 2: Symptoms of dysmenorrhoea.

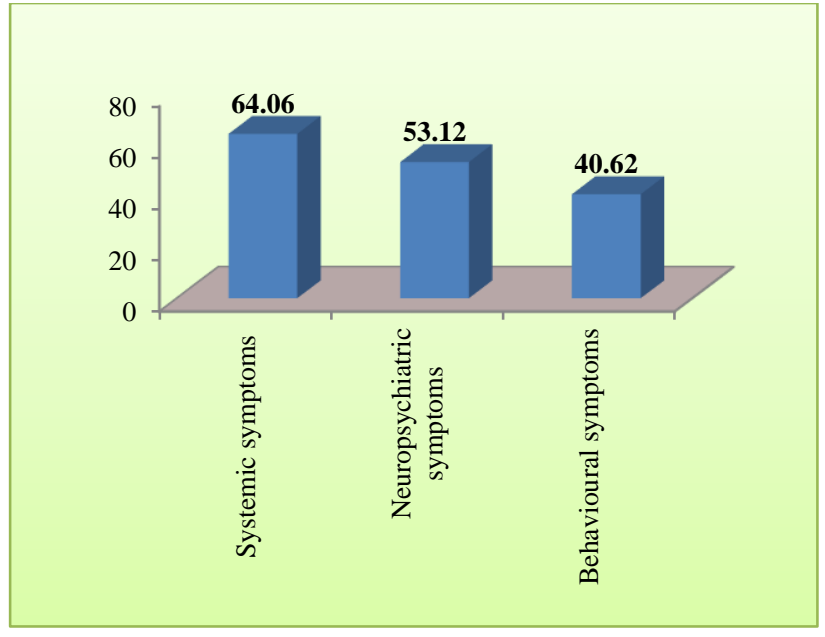

Figure 3: Premenstrual symptoms.

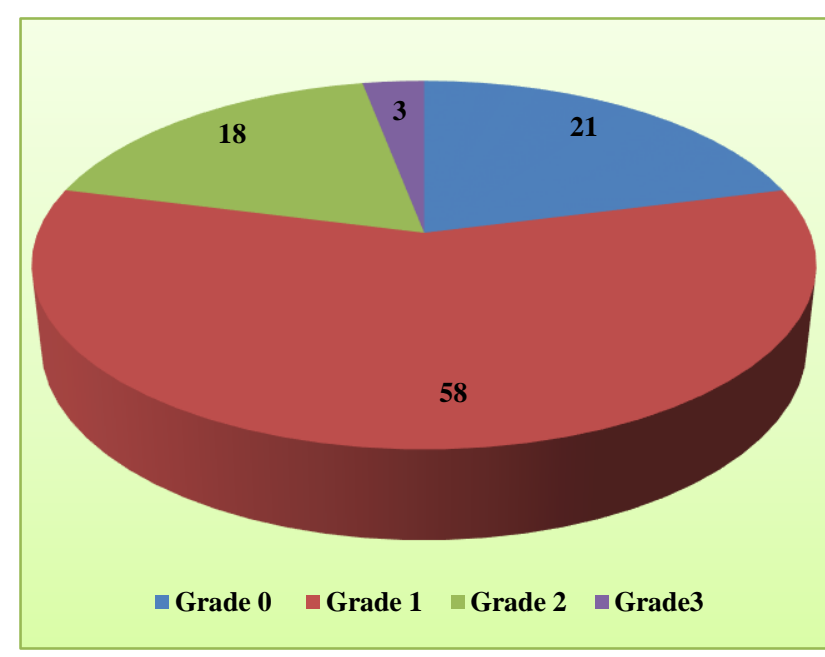

Figure 4: Severity of dysmenorrhoea grading (verbal multidimensional scoring system).

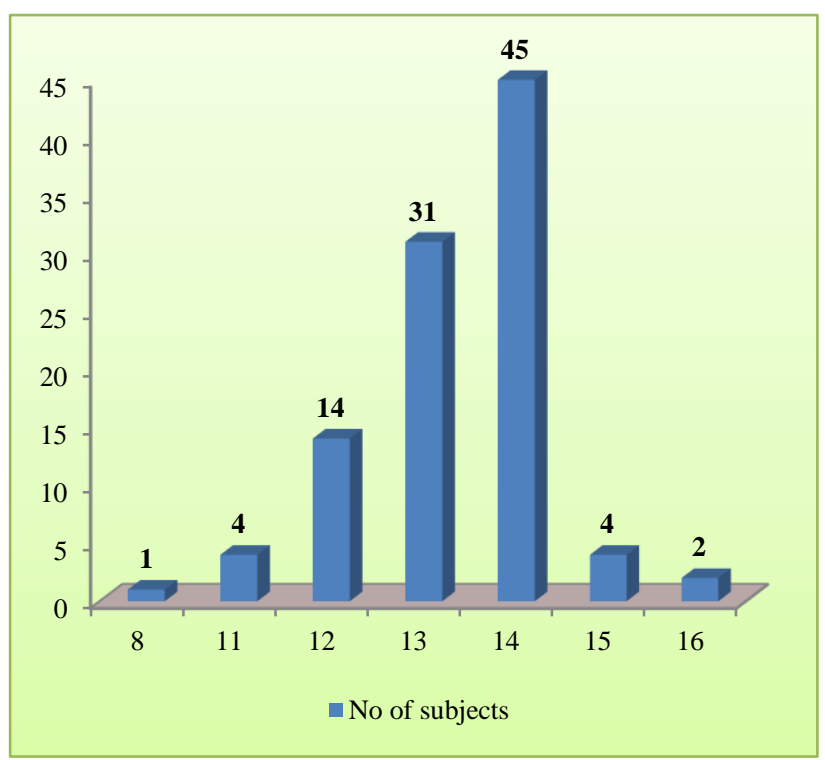

Figure 5: Distribution of subjects according to age of menarche. 
Out of 79/100 participants $25 / 79(31.64 \%)$ were absent from college/work place, 50/79 (63.29\%) missed individual classes/affected study and $41 / 79$ (51.89\%) reported social withdrawal during menstruation due to dysmenorrhoea. 6/79 $(7.59 \%)$ subjects had to take medicines for relief of pain of dysmenorrhoea (Table 4).

Table 4: Effect of Dysmenorrhoea on life quality.

\begin{tabular}{|lcl|}
\hline Routine activities & $\begin{array}{l}\mathrm{n} / \mathrm{d} \\
(\%)\end{array}$ & $\begin{array}{l}95 \% \\
\text { Confidence } \\
\text { Interval }\end{array}$ \\
\hline Absenteeism from work place & 31.64 & $21.63-43.08$ \\
\hline Affected study/poor concentration & 63.29 & $51.69-73.86$ \\
\hline Social withdrawal during menses & 51.89 & $40.36-63.29$ \\
\hline T/t required for dysmenorrhoea & 7.59 & $2.84-15.80$ \\
\hline
\end{tabular}

Table 5: Severity of dysmenorrhoea grading (verbal multidimensional scoring system).

\begin{tabular}{|lll|}
\hline Grading & $\begin{array}{l}\text { No of students } \\
(\mathbf{n}=\mathbf{1 0 0})\end{array}$ & $\mathbf{9 5 \%}$ Confidence interval \\
\hline Grade 0 & 21 & $13.49-30.29$ \\
\hline Grade 1 & 58 & $47.71-67.80$ \\
\hline Grade 2 & 18 & $11.03-26.95$ \\
\hline Grade3 & 3 & $0.62-8.52$ \\
\hline
\end{tabular}

\section{DISCUSSION}

Among the 100 participants, the average age of participant was 19.28 years ranging from 17 to 22 years. In similar study Mool Raj Kural et al., the average age of participant was $20.4 \pm 1.8$ years ranging from 17 to 25 years and in another similar study Unsal et al, average age of participants was $20.8 \pm 1.8$ years. ${ }^{12,13}$

In the present study association of dysmenorrhoea with particular age was not found significant. $73 \%$ belongs to urban and $27 \%$ from rural area. association of dysmenorrhoea with locality not found significant $(\mathrm{p}=0.420)$, but greater chance of dysmenorrhoea found in rural area. Avasarala et al, also not reported any association of dysmenorrhoea with locality. ${ }^{14}$

Out of 79 subjects of dysmenorrhoea 54/79 subjects had average BMI, while 16/79 subjects found underweight, $7 / 79$ overweight and 2/79 obese. Association of dysmenorrhoea was not fount stastistically significant with BMI $(\mathrm{P}=0.953)$ while $\mathrm{Ju} \mathrm{H}$ et al., found higher association of dysmenorrhea with women who were underweight and obese. ${ }^{15}$ In Shah $\mathrm{M}$ et al., $4.31 \%$ were underweight, $84.48 \%$ were average weight and $11.20 \%$ were overweight. ${ }^{16}$

In Unsal A et al, overweight and obesity was found in $6.4 \%$ participants. 27 participants did no physical exercise, 28 exercise for $<30$ minutes and $45 \%$ exercise for $\geq 30$ minutes. ${ }^{13}$ In the present study dysmenorrhoea was found in $26 / 27,25 / 28$ and $28 / 45$ subjects with no physical exercise, <30 min exercise and $>30 \mathrm{~min}$ of exercise respectively. Association of dysmenorrhoea was found highly significant with duration of exercise ( $\mathrm{p}=0.001)$, Onur $\mathrm{O}$ et al, study show that exercise has a positive effect on dysmenorrhea. ${ }^{17}$ Out of 66 subjects having fast food habit dysmenorrhoea was present in 56, while out of 34 subjects with no fast food habit dysmenorrhoea was present in 23 cases. This was found statistically significant $(\mathrm{p}=0.045)$. Jaget $\mathrm{N}$ et al and Lakshmi AS. also found significant association between fast food habit with dysmenorrhoea. ${ }^{18,19}$

Prevalence of dysmenorrhoea in the present study was $79 \%$ which was in agreement with Prevalence rate reported by study from Gondar University, Private University in Ogun state and Alaettin Unsal et al, which were $77.6 \%, 78.1 \%$ and $72.7 \%$, respectively. ${ }^{13,20,21}$ In Shrotriya Charu et el the prevalence was 67\%. Mild degree of dysmenorrhoea reported in $58 \%$ cases, moderate and severe degree were reported in 18 and $3 \%$ of cases respectively.

In study by Sharma $\mathrm{N}$ et al mild, moderate and severe degree were noted in $36.5 \%, 24.6 \%$ and $9.5 \%$ respectively, while Singh A, reported prevalence of dysmenorrhea was $73.83 \%$; of these $6.32 \%$, severe, $30.37 \%$ moderate and $63.29 \%$ were mild grade. ${ }^{22}$ Length of cycle was $<20$ days in $3 \%$ participants, 20 to 35 days in $85 \%$ and $>35$ days in $12 \%$.

In Minaleshewa Biruk et al., it was $6.4 \%, 76.40 \%$ and $17.2 \%$ respectively. In Shrotriya Charu et al., $97 \%$ had 28-35 days of cycle length which is normal. Duration of flow in present study was <2 days in 3\%, 3-7 days in $93 \%$ and $>7$ days in $4 \%$ of participants. ${ }^{21}$ In Minaleshewa Biruk et al., $62 \%$ participants had duration of flow of 3-4 days. ${ }^{20}$ In Alaettin Unsal et al., duration of flow was $<6$ days in $68.7 \%$ and $\geq 7$ days $31.3 \% .^{13}$ Blood loss per cycle assessed by number of pads used per cycle and found to be use of $\leq 5$ pads in $6 \%, 6-10$ pads in $48 \%, 11-15$ pads in $33 \%, 16-20$ pads in $8 \%$ and $>20$ pads in $5 \%$ participants. In present study premenstrual symptoms were present in $64 \%$ of participants. In Charu S et al $86.96 \%$ had physical premenstrual symptoms and psychological PMS were in $56 \% .^{2}$

In the present study, subjects suffering from dysmenorrhoea $(n=79)$ presented with the following symptoms like abdominal cramps $(84.81 \%)$ backache $(82.27 \%)$, fatigue $(54.43 \%)$, headache $(32.91 \%)$ vomiting $(15.18 \%)$ and other symptoms like diarrhea, tachycardia, mood changes $(15.18 \%)$. Among these most common symptoms were abdominal cramp and headache similar to study conducted by Derseh BT et al. ${ }^{23}$ Rahma Al reported backache (79\%), stomach cramps (70\%) and mood changes $(68 \%)$ cases

In the present study about $3164 \%$ were absent from class/work place, $51.89 \%$ had encountered social withdrawal similarly Minaleshewa Biruk Gebeyehu et al., 
found absentesim from classes and social withdrawal in $31.1 \%$ and $63 \%$ respectively, while in hongkong university study affected in $75 \% .{ }^{24}$ Despite such an impact on their lives, only $7.59 \%$ take medicines or sought formal medical advice for their dysmenorrhoea. Which was similar to study of Hongkong university students. ${ }^{25}$

\section{CONCLUSION}

Dysmenorrhoea is common among the nursing students and it is major problem representing the leading cause of college/class/ work place absenteeism. Although further research is needed.

Funding: No funding sources Conflict of interest: None declared

Ethical approval: The study was approved by the Institutional Ethics Committee

\section{REFERENCES}

1. Weissman AM, Hartz AJ, Hansen MD, Johnson SR. The natural history of primary dysmenorrhoea: a longitudinal study. BJOG: An Int J Obstet and Gynaecol. 2004;111:345-52.

2. Charu S, Amita R, Sujoy R, Thomas GA. Menstrual characteristics' and 'prevalence and effects of dysmenorrhea'on quality of life of medical students. Int J Collab Res Internal Med Public Health. 2012;4:276-94.

3. Burnett MA, Antao V, Black A, Feldman K, Grenville A, Lea R, et al. Prevalence of primary dysmenorrhea in Canada. J Obstet Gynaecol Can. 2005;27:765-70.

4. Pitts MK, Ferris JA, Smith AM, Shelley JM, Richters J. Prevalence and correlates of three types of pelvic pain in a nationally representative sample of Australian women. Med J Aust. 2008;189:138-43.

5. Nur N, Sümer H. Prevalence of dysmenorrhea and related risk factors in adolescents. Surekli Tip Egitimi Dergisi. 2008;7:27-30.

6. Polat A, Celik H, Gurates B, Kaya D, Nalbant M, Kavak E, et al. Prevalence of primary dysmenorrhea in young adult female university students. Arch Gynecol Obstet. 2009;279:527-32

7. Sharma N, Sagayaraj M, Sujatha B. Menstrual characteristics and prevalence of dysmenorrhea in college students. Int J Scienti Res Publica. 2014;4:16.

8. Berkley KJ. Primary dysmenorrhea: an urgent mandate. Int Assoc Study Pain. 2013;21:1-8.

9. Shiferaw MT, Wubshet M, Tegabu D. Menstrual problems and associated factors among students of Bahir Dar University, Amhara National Regional State, Ethiopia: A cross-sectional survey. Pan Afr Medi J. 2014;17:246.

10. Andersch B, Milsom I. An epidemiologic study of young women with dysmenorrhea. Am J Obstet Gynecol. 1982;144:655-60.
11. Banikarim C, Chacko MR, Kelder SH. Prevalence and impact of dysmenorrhea on Hispanic female adolescents. Arch Pediatr Adolesc Med. 2000;154:1226-9.

12. Kural M, Noor NN, Pandit D, Joshi T, Patil A. Menstrual characteristics and prevalence of dysmenorrhea in college going girls. J Family Med Prim Care. 2015;4:426-31

13. Unsal A, Ayranci U, Tozun M, Arslan G, Calik E. Prevalence of dysmenorrhea and its effect on quality of life among a group of female university students. Upsala J Med Sci. 2010;115:138-45.

14. Avasarala KA, Panchangam S. Dysmenorrhoea in Different Settings: Are the Rural and Urban Adolescent Girls Perceiving and Managing the Dysmenorrhoea Problem Differently? Indian J Community Med. 2008;33:246-9.

15. Ju H, Jones M, Mishra GD. A U-shaped relationship between Body Mass Index and dysmenorrhea: A Longitudinal study. PLoS ONE 2015;10:e0134187.

16. Shah M, Monga A, Patel S, Shah M, Bakshi H. A study of prevalence of primary dysmenorrhea in young students-A cross-sectional study. Healthline. 2013;4:30-4.

17. Onur O, Gumus I, Derbent A, Kaygusuz I, Simavli $\mathrm{S}$, Urun E, Yildirim M, Gok K, Cakirbay H. Impact of home-based exercise on quality of life of women with primary dysmenorrhea. South Afr J Obstet Gynecol. 2012;18(1).

18. Lakkawar NJ, Jayavani RL, Arthi NP, Alaganandam P, Vanajakshi N. A study of menstrual disorders in medical students and its correlation with biological variables. Sch J App Med Sci. 2014;2(6E):3165-75.

19. Anandha Lakshmi S, Priy M, Saraswathi I, Saravanan A, Ramamchandran C. Prevalence of premenstrual syndrome and dysmenorrhoea among female medical students and its association with college absenteeism. Int $\mathbf{J}$ Biol Med Res. 2011;2(4):1011-6.

20. Gebeyehu MB, Mekuria AB, Tefera YG, Andarge DA, Debay YB, Bejiga GS, Gebresillassie BM. Prevalence, impact, and management practice of dysmenorrhea among University of Gondar Students, Northwestern Ethiopia: a cross-sectional study. Int J Reprod Med. 2017;2017:3208276.

21. Grandi, Ferrari S, Xholli A. Prevalence of menstrual pain in young women: what is dysmenorrhea? Jo Pain Res. 2012;5:169-74.

22. Singh A, Kiran D, Singh H, Nel B, Singh P, Tiwari P. Prevalence and severity of dysmenorrhea: A problem related to menstruation, among first and second year female medical students. Indian J Physiol Pharmacol. 2008;52(4):389-397

23. Derseh BT, Afessa N ,Temesgen M, Semayat YW, Kassaye $M$ et al. Prevalence of Dysmenorrhea and its Effects on School Performance: A Cross-sectional Study. J Women Health Care. 2017;6:361.

24. Rahma Al-kindi and Anbarin Al-Bulashi. Prevalence and impact of Dysmenorrhoea among omani High 
school students; Sultan Quboos Univ Med J. 2011;11:485-91.

25. Chia CF, Lai JH, Cheung PK, Kwong LT, Lau FP, Leung $\mathrm{KH}$ et al., Dysmenorrhoea among Hong Kong university students: prevalence, impact, and management. Hong Kong Med J. 2013;19:222-8.
Cite this article as: Ghanghoriya V, Patel K, Markam R. Prevalence of dysmenorrhoea and its effect on quality of life among nursing students. Int $\mathbf{J}$ Reprod Contracept Obstet Gynecol 2018;7: 2129-35. 